\title{
Dependence of Performance of Si Nanowire Solar Cells on Geometry of the Nanowires
}

\author{
Firoz Khan, Seong-Ho Baek, and Jae Hyun Kim \\ Energy Research Division, Daegu Gyeongbuk Institute of Science \& Technology (DGIST), 50-1 Sang-Ri, Hyeonpung-Myeon, \\ Dalseong-gun, Daegu 711-873, Republic of Korea
}

Correspondence should be addressed to Jae Hyun Kim; jaehyun@dgist.ac.kr

Received 30 August 2013; Accepted 7 November 2013; Published 16 January 2014

Academic Editors: H. Aras and F. Zhang

Copyright (C) 2014 Firoz Khan et al. This is an open access article distributed under the Creative Commons Attribution License, which permits unrestricted use, distribution, and reproduction in any medium, provided the original work is properly cited.

The dependence of performance of silicon nanowires (SiNWs) solar cells on the growth condition of the SiNWs has been described. Metal-assisted electroless etching (MAE) technique has been used to grow SiNWs array. Different concentration of aqueous solution containing $\mathrm{AgNO}_{3}$ and $\mathrm{HF}$ for Ag deposition is used. The diameter and density of SiNWs are found to be dependent on concentration of solution used for Ag deposition. The diameter and density of SiNWs have been used to calculate the filling ratio of the SINWs arrays. The filling ratio is increased with increase in $\mathrm{AgNO}_{3}$ concentration, whereas it is decreased with increase in $\mathrm{HF}$ concentration. The minimum reflectance value achieved is $\sim 1 \%$ for SiNWs of length of $\sim 1.2 \mu \mathrm{m}$ in the wavelength range of 300-1000 nm. The performance and diode parameters strongly depend on the geometry of SiNWs. The maximum short circuit current density achieved is $35.6 \mathrm{~mA} / \mathrm{cm}^{2}$. The conversion efficiency of solar cell is $9.73 \%$ for SiNWs with length, diameter, and wire density of $\sim 1.2 \mu \mathrm{m}, \sim 75 \mathrm{~nm}$, and $90 \mu \mathrm{m}^{-2}$, respectively.

\section{Introduction}

The increasing demand for energy and the effect of global warming are two related issues attracting more and more attention from human being. Photovoltaic technology is the most promising approach to carbon-free energy production and it has received more attention [1]. Nanostructures can be used as solution for better photovoltaic application [2]. The photovoltaic based on silicon nanowires (SiNWs) are becoming more attractive due to their optical and electrical properties compared to bulk Si $[3,4]$. The important role of SiNWs arrays is to reduce reflection losses in photovoltaic devices. The reduction in the reflectance of SiNWs arrays is due to improved optical impedance matching between air and $\mathrm{Si}$ $[5,6]$, multiple incident light scattering inside the arrays [7], and the role of individual SiNWs as nanoscale resonators with the antenna effect [8]. Several techniques have been reported in the literature to synthesize the SiNWs [9-11].

Several studies have been made to design the structural parameters, namely, filling ratio, wire density, and diameter, to enhance light absorption in SiNWs solar cells $[12,13]$. Some of the researchers $[14,15]$ have done the simulation for diameter and periodicity ratio dependence on the optical absorption in the SiNWs arrays [16-18]. Previously, some of the groups [19-21] investigated that randomly distributed SiNWs array gives better absorption than the regularly distributed one due to stronger scattering. Metal-assisted electroless etching (MAE) technique has been recently developed for fabrication of randomly distributed SiNWs arrays [2224]. It is important to design particular diameter and wire density (periodicity) to achieve minimum reflectance and hence to get the highest current density for SiNWs based solar cells. Secondly, reduction of the recombination and resistive losses are equally important to get the better conversion efficiency. The reflectance can be easily reduced by increasing the length of SiNWs but recombination and resistive losses also increase with the increase in SiNWs length. Thus, the SiNWs of smaller length with ultralow reflectance are potentially feasible for antireflection applications in next-generation solar cells [22-26]. Hence, it is important to optimize the geometrical parameters for obtaining SiNWs arrays as superior antireflective characteristics with minimum recombination and resistive losses. Recently, Jung et al. [27] have optimized Ag deposition time to get maximum conversion efficiency. 
In this paper, we have tried to achieve minimum reflectance $\sim 1 \%$ in the wavelength range $300-1000 \mathrm{~nm}$ by engineering the diameter and density of SiNWs of length $\sim 1.2 \mu \mathrm{m}$ to get the minimum reflection, recombination and resistive losses.

\section{Materials and Methods}

2.1. Synthesis of SiNWs. SiNWs arrays were synthesized on $\mathrm{Cz}$ grown, boron doped p-type, $0.2-0.6 \Omega \mathrm{cm}$ resistivity, $550 \mathrm{~mm}$ thickness, and $<100>$ oriented polished Si wafers using two steps metal-assisted wet etching (metal deposition and etching) method. First, the substrates were cleaned in hot solution of $\mathrm{H}_{2} \mathrm{O}_{2}$ and $\mathrm{H}_{2} \mathrm{SO}_{4}(1: 3$ by volume) for $10 \mathrm{~min}$. Then, the substrates were dipped in dilute $\mathrm{HF}$ to remove oxide grown in the cleaning process. The silver nanoparticles (NPs) were uniformly deposited onto the Si substrate using an aqueous solution of $\mathrm{AgNO}_{3}$ and HF. Two types of solutions ( $\mathrm{A}$ and $\mathrm{B}$ ) were used separately for $\mathrm{Ag}$ deposition for two sets of experiments. In set $\mathrm{A}$, the concentration of $\mathrm{AgNO}_{3}$ was taken as $0.01,0.02,0.03$, and $0.04 \mathrm{M}$ (i.e., set $\mathrm{A}_{1}, \mathrm{~A}_{2}, \mathrm{~A}_{3}$, and $\mathrm{A}_{4}$ ) and the concentration of $\mathrm{HF}$ was constant $(4.6 \mathrm{M})$. In set $\mathrm{B}$, the concentration of $\mathrm{AgNO}_{3}$ was constant $(0.03 \mathrm{M})$ and the concentration of $\mathrm{HF}$ was taken as 2.3, 4.6, 6.9, and 9.2 $\mathrm{M}$ (i.e., set $\mathrm{B}_{1}, \mathrm{~B}_{2}, \mathrm{~B}_{3}$, and $\mathrm{B}_{4}$ ). Henceforth, we shall refer to the samples simply as $A_{1}, A_{2}, A_{3}, A_{4}, B_{1}, B_{2}, B_{3}$, and $B_{4}$ in the text. It can be noted that the samples $A_{3}$ and $B_{2}$ were identical because the solution concentration was same. In the Ag deposition process, the Ag ions captured electrons from $\mathrm{Si}$ and reduced to Ag metal NPs. These nanoparticles are deposited on the silicon surfaces. The areal density of Ag NPs depends upon solution concentration, deposition time, and temperature. The etching was performed at room temperature in a mixed solution of deionized water (DIW), $\mathrm{HF}(4.6 \mathrm{M})$, and $\mathrm{H}_{2} \mathrm{O}_{2}(0.5 \mathrm{M})$ to obtain a vertically aligned SiNWs array. After completing the electroless etching, SiNW samples were dipped in concentrated $\mathrm{HNO}_{3}$ for $10 \mathrm{~min}$ to completely remove the remaining Ag NPs, then rinsed in DIW, and dried in air. The filling ratio was calculated using method of Jung et al. [27].

2.2. Solar Cell Fabrication. The SiNWs samples were subjected to RCA cleaning before the fabrication process. After RCA cleaning, the front and back sides were simultaneously diffused by phosphorous and boron using phosphorussilicate and borosilicate glass to create $n^{+}-p-p^{+}$structure by spin on dopant (SOD) technique. Phosphorus and boron silicate precursors (P509 for P and B200 for B, supplied by Filmtronics) were spin-coated on different dummy wafers. Then, the SiNWs samples were loaded between the dummy wafers in a conventional quartz-tube furnace. The diffusion was carried out at $1000^{\circ} \mathrm{C}$ for $5 \mathrm{~min}$, while the target samples were kept at a closely spaced distance.

After diffusion, the phosphosilica glass (PSG) and borosilica glass (BSG) were removed simply by immersing the prepared specimens in buffer oxide etchant (BOE) for $10 \mathrm{~min}$. The patterned front gridded metal contacts were made by $\mathrm{Ti} / \mathrm{Ag}$ using metal mask. The back contacts were made using
$\mathrm{Ti} / \mathrm{Ag}$ on the full surface. The contacts were sintered in rapid thermal processing unit (RTP) at $600^{\circ} \mathrm{C}$. Finally, edges of the solar cells were scribed for isolation of junction.

2.3. Characterization Techniques. The field emission scanning electron microscopy (FE-SEM) images were taken for front and cross-sectional views of SiNWs samples using Hitachi FE-SEM Model S-4800. The reflectance of SiNWs samples was measured in the wavelength range of 300-1200 nm with Perkin-Elmer Model Lambda 750 using an integrated sphere.

The illuminated current density-voltage $(J-V)$ characteristics of solar cells were measured under $100 \mathrm{~mW} / \mathrm{cm}^{2}$ intensity with AM1.5 Global spectrum using a Keithley sourcemeter Model 2400 (with basic accuracy 0.012\%) and Newport 91192 solar simulator system (equipped with 1KW Xenon arc lamp from Oriel). The illumination intensity was measured using a reference silicon solar cell obtained from PV Measurements, USA. All the measurements were carried out at $25^{\circ} \mathrm{C}$.

\section{Results and Discussion}

3.1. Geometry of SiNWs Array. The front and cross-sectional (in inset) views of SiNWs arrays of both sets are shown in Figures 1(a)-1(d) and Figures 2(a)-2(d), respectively. It can be seen from Figures 1(a)-1(d) that the surface morphology (number of SiNWs per unit area and diameter of SiNWs) is changing with the $\mathrm{AgNO}_{3}$ concentration. The diameter of SiNWs is decreased with increase in $\mathrm{AgNO}_{3}$ concentration, whereas the SiNWs density (number of SiNWs per unit area) is increased with increase in the $\mathrm{AgNO}_{3}$ concentration. The variation of SiNWs (wire) diameter and density is shown in Figure 3 . The increase in wire density may be due to increase in number of $\mathrm{Ag}$ nanoparticles with increase in $\mathrm{AgNO}_{3}$ concentration. The reduction in wire diameter may be due to decrease in the Ag nanoparticles size with increase in $\mathrm{AgNO}_{3}$ concentration. The variation of wire diameter and density with HF concentrations is shown in Figure 4. Both the wire diameter and density are decreased with increase in HF concentration. The diameter of the wires is initially decreased with fast rate then becomes slower. The wire density is decreased linearly with increase in HF concentration. The value of diameters and densities of wires has been used to calculate the filling ratio of SiNWs arrays. The variation of filling ratio of $\mathrm{SiNW}$ s with $\mathrm{AgNO}_{3}$ and $\mathrm{HF}$ concentration are shown in Figure 5. The filling ratio is linearly increased with increase in $\mathrm{AgNO}_{3}$ concentration, whereas it is exponentially decreased with the increase in HF concentration.

3.2. Dependence of Reflectance of SiNWs Arrays on Growth Condition. The reflectance spectra of all the samples are shown in Figure 6. The minimum reflectance of $\sim 1 \%$ is observed for samples $A_{3}$ and $B_{2}, B_{3}$, and $B_{4}$ in the wavelength range $600-800 \mathrm{~nm}$, whereas, in the wavelength range of $300-$ $1000 \mathrm{~nm}$, sample $B_{3}$ has the lowest reflectance value. It can be noted that the minimum reflectance is obtained for filling ratio of $\sim 40 \%$. In case of samples $B_{3}$ and $B_{4}$, the length 


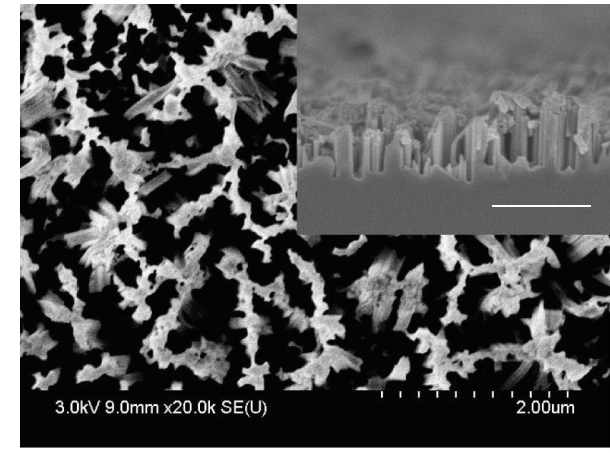

(a)

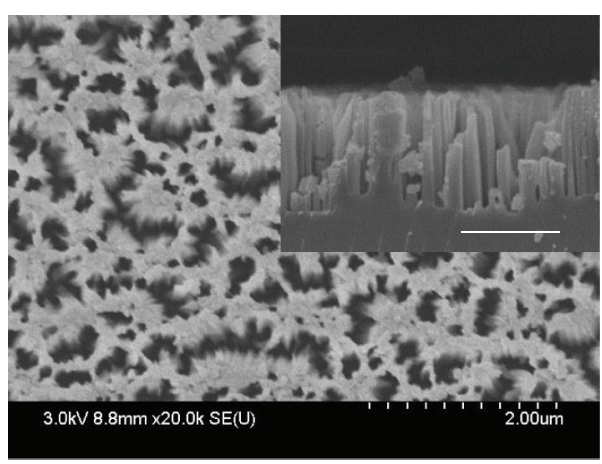

(c)

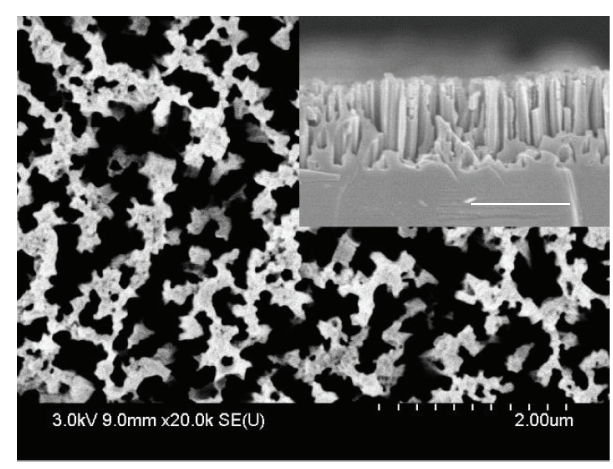

(b)

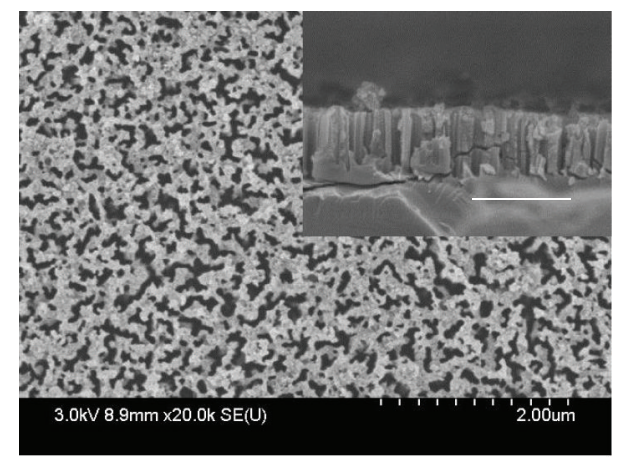

(d)

Figure 1: FE-SEM images of front and cross-sectional (in inset) view of SiNWs array grown using solutions (a) $A_{1}$, (b) $A_{2}$, (c) $A_{3}$, and (d) $A_{4}$ for Ag deposition.

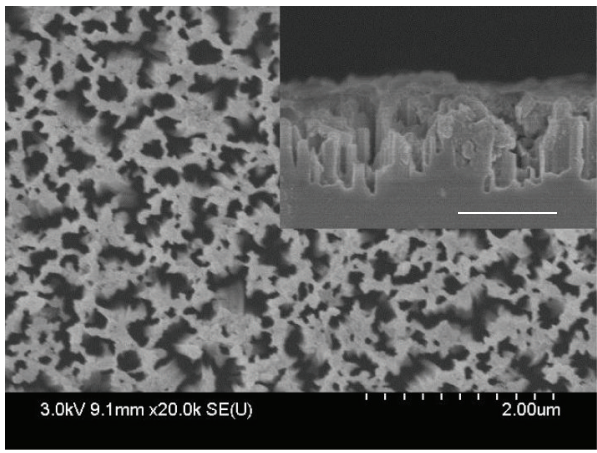

(a)

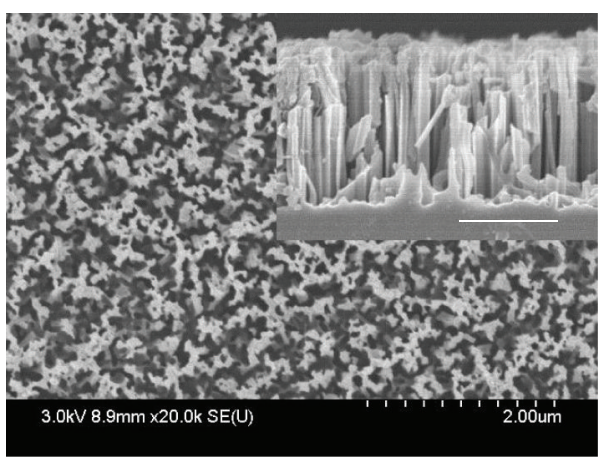

(c)

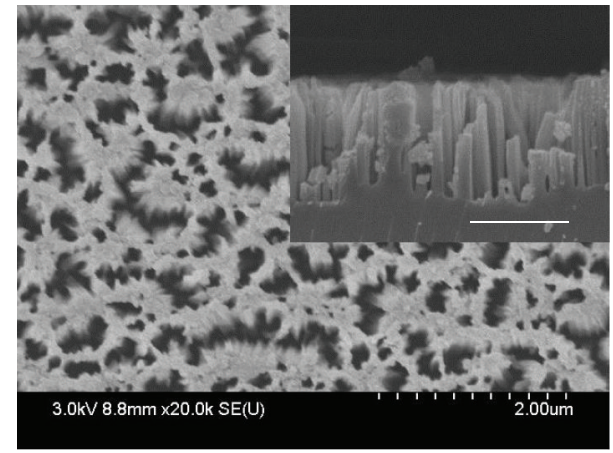

(b)

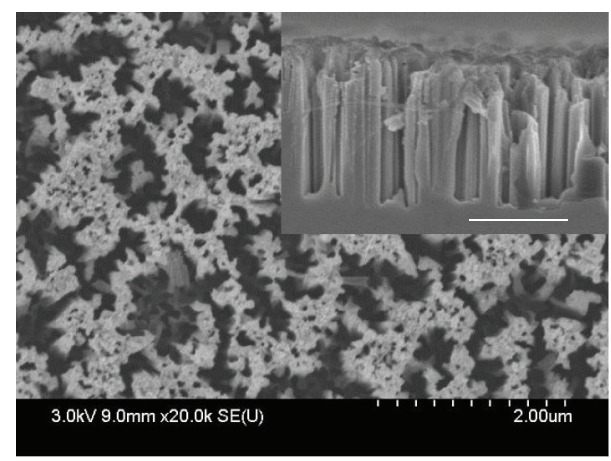

(d)

FIGURE 2: FE-SEM images of front and cross-sectional (in inset) view of SiNWs array grown using solutions (a) $B_{1}$, (b) $B_{2}$, (c) $B_{3}$, and (d) $B_{4}$ for Ag deposition. 
TABLE 1: The values of performance parameters obtained at $25^{\circ} \mathrm{C}$ under $100 \mathrm{~mW} / \mathrm{cm}^{2}$ intensity of simulated AM1.5G solar radiation along with their reflectance at wavelength $\lambda=600 \mathrm{~nm}$.

\begin{tabular}{|c|c|c|c|c|c|}
\hline Sample & $R(\%)$ at $\lambda=600 \mathrm{~nm}$ & $J_{\mathrm{sc}}\left(\mathrm{A} / \mathrm{cm}^{2}\right)$ & $V_{\mathrm{oc}}(\mathrm{V})$ & CF & $\eta(\%)$ \\
\hline$A_{1}$ & 2.43 & 0.0250 & 0.521 & 0.555 & 7.23 \\
\hline $\mathrm{A}_{2}$ & 1.51 & 0.0251 & 0.529 & 0.597 & 7.93 \\
\hline$A_{3} \& B_{2}$ & 1.22 & 0.0343 & 0.534 & 0.531 & 9.73 \\
\hline $\mathrm{A}_{4}$ & 1.41 & 0.0325 & 0.531 & 0.501 & 8.65 \\
\hline $\mathrm{B}_{1}$ & 1.62 & 0.0266 & 0.526 & 0.525 & 7.35 \\
\hline $\mathrm{B}_{3}$ & 0.93 & 0.0349 & 0.523 & 0.357 & 6.52 \\
\hline $\mathrm{B}_{4}$ & 0.94 & 0.0356 & 0.524 & 0.374 & 6.98 \\
\hline
\end{tabular}

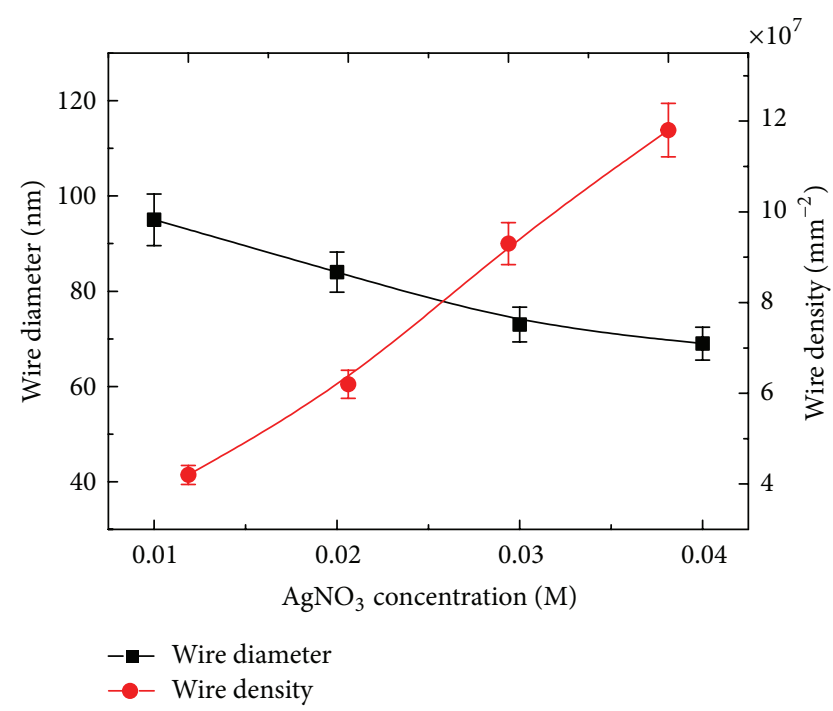

FIGURE 3: Variation of average diameters and density of SiNWs with $\mathrm{AgNO}_{3}$ concentration.

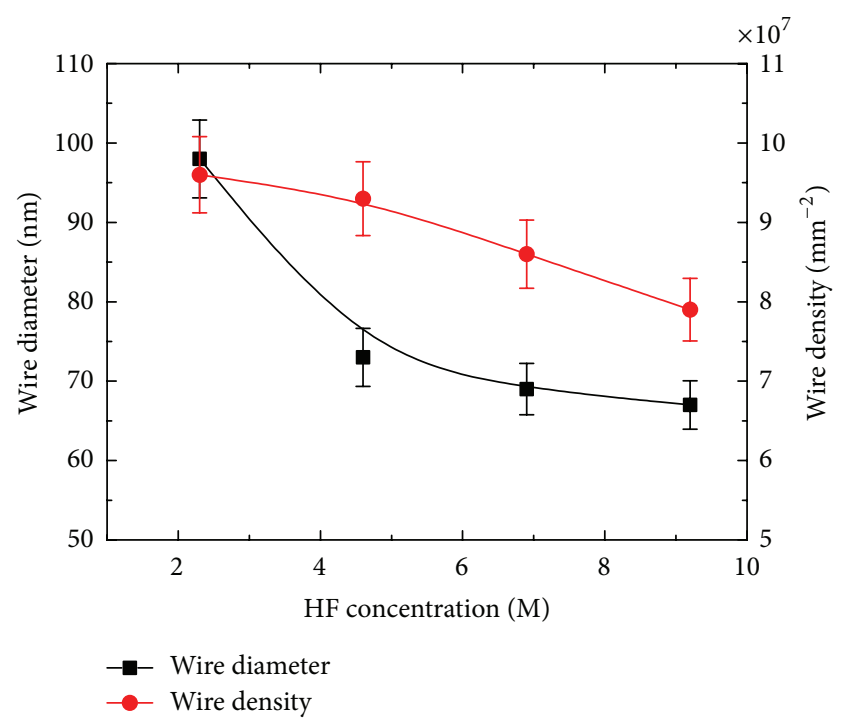

FIGURE 4: Variation of average diameter and density of SiNWs with HF concentration.

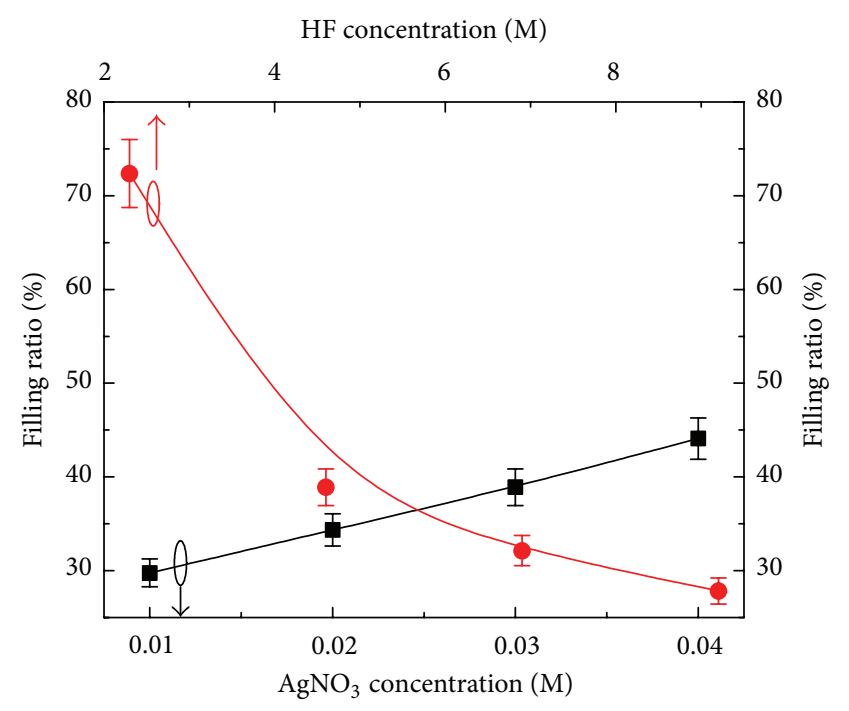

Figure 5: Dependence of filling ratio of SiNWs array with $\mathrm{AgNO}_{3}$ and HF concentrations.

$(\sim 1.5 \mu \mathrm{m})$ of nanowires is greater than in the all others samples $(\sim 1.2 \mu \mathrm{m})$ for the same Ag deposition time and the same etching conditions. The highest $(\sim 2.43 \%)$ and the lowest $(\sim$ $0.93 \%)$ values of reflectance are obtained for the samples $A_{1}$ and $\mathrm{B}_{3}$, respectively.

3.3. Analysis of Performance Parameters. The illuminated $J-V$ curves obtained at $25^{\circ} \mathrm{C}$ under illumination condition of $100 \mathrm{~mW} / \mathrm{cm}^{2}$ of simulated AM1.5G solar radiation of the above samples are shown in Figure 7. It can be seen from Figure 7 the maximum value of conversion efficiency obtained for samples $A_{3}$ and $B_{2}$. The performance parameters, namely, short circuit current density $J_{\text {sc }}$, open circuit voltage $V_{\text {oc }}$, curve factor $\mathrm{CF}$, and conversion efficiency $\eta$ of the solar cells, are listed in Table 1. The current densities of samples $B_{3}$ and $B_{4}$ are higher than those of the samples $A_{3}$ and $B_{2}$ due to lowest reflection in the wavelength range of 300-1200 nm but conversion efficiencies are very low due to low $\mathrm{CF}$ values. The highest and the lowest $J_{\mathrm{sc}}$ values are obtained as 35.6 and $25.0 \mathrm{~mA} / \mathrm{cm}^{2}$ for the samples $A_{1}$ and $\mathrm{B}_{4}$, respectively. The maximum achieved $V_{\text {oc }}$ value is $0.534 \mathrm{~V}$ for samples $A_{3}$ and $B_{2}$. The minimum and maximum $C F$ 
TABLE 2: The values of diode parameter (shunt resistance, series resistance, diode ideality factor, and reverse saturation current density) obtained at $25^{\circ} \mathrm{C}$ from illuminated $J-V$ curves.

\begin{tabular}{lcccr}
\hline Sample & $R_{\mathrm{sh}}\left(\Omega \mathrm{cm}^{2}\right)$ & $R_{s}\left(\Omega \mathrm{cm}^{2}\right)$ & $n$ & $J_{0}\left(\mathrm{~A} / \mathrm{cm}^{2}\right)$ \\
\hline $\mathrm{A}_{1}$ & 251.88 & 2.222 & 2.364 & $4.276 E-6$ \\
$\mathrm{~A}_{2}$ & 452.49 & 2.625 & 1.788 & $2.363 E-7$ \\
$\mathrm{~A}_{3} \& \mathrm{~B}_{2}$ & 204.92 & 2.736 & 2.713 & $1.479 E-5$ \\
$\mathrm{~A}_{4}$ & 645.16 & 3.415 & 2.531 & $8.937 E-6$ \\
$\mathrm{~B}_{1}$ & 380.22 & 3.329 & 2.444 & $5.749 E-6$ \\
$\mathrm{~B}_{3}$ & 45.72 & 2.058 & 5.356 & $5.211 E-4$ \\
$\mathrm{~B}_{4}$ & 55.31 & 2.190 & 5.040 & $4.575 E-4$ \\
\hline
\end{tabular}

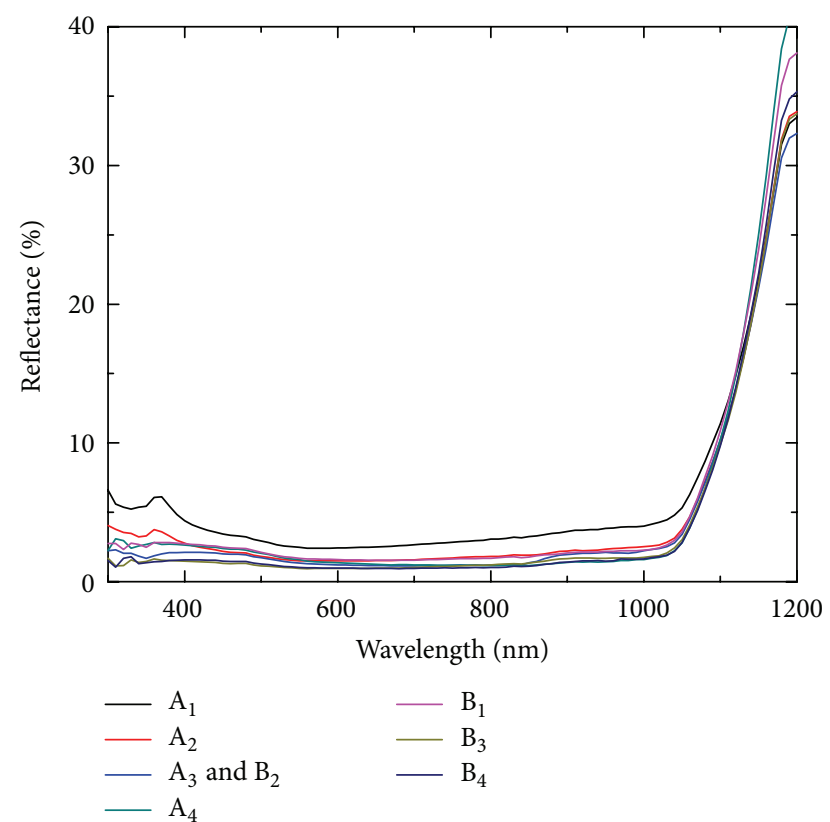

FIGURE 6: Reflectance spectra of SiNWs arrays grown, using different solutions for Ag deposition.

values obtained are 0.357 and 0.597 for samples $B_{3}$ and $A_{2}$, respectively. A low $C F$ value of sample $B_{3}$ is mainly due to the lower value of shunt resistance $\left(R_{\mathrm{sh}}\right)$. A lower value $V_{\mathrm{oc}}$ is obtained for the samples $\mathrm{B}_{3}$ and $\mathrm{B}_{4}$ due to the low value of $R_{\text {sh }}$, high surface recombination velocity. The length of nanowires of samples $B_{3}$ and $B_{4}$ is higher $(\sim 1.5 \mu \mathrm{m})$ than that of the other samples, so the surface recombination velocity is increased due to increase in active surface area (number of dangling bonds). The low $\mathrm{CF}$ values of the samples $\mathrm{B}_{3}$ and $\mathrm{B}_{4}$ are mainly due to high series resistance $\left(R_{s}\right)$. The highest conversion efficiency of $9.73 \%$ is obtained for samples $A_{3}$ and $\mathrm{B}_{2}$.

3.4. Analysis of Diode Parameters. The values of $R_{\mathrm{sh}}, R_{s}$, diode ideality factor $(n)$, and reverse saturation current density $\left(J_{0}\right)$ are listed in Table 2. The $R_{\mathrm{sh}}$ values of samples $\mathrm{B}_{3}$ and $\mathrm{B}_{4}$ (45.72 and 55.31, resp.) are lower among all the samples (more than $200 \Omega \mathrm{cm}^{2}$ ) due to high porosity (low filling ratio). The low filling ratio is resulted to slightly puncture the junction that increased the shunt current. Due to larger surface area

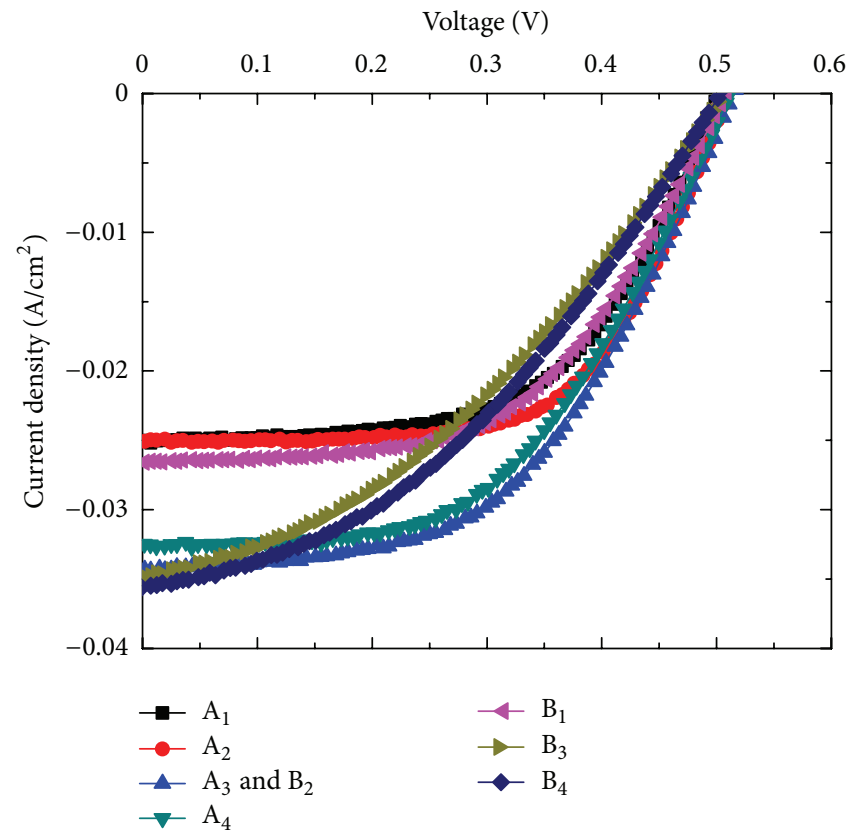

FIGURE 7: Illuminated $J-V$ characteristics of solar cells with SiNWs grown, using different solutions for Ag deposition.

of the samples $B_{3}$ and $B_{4}$, the surface recombination is high which increased the values of $n$ and $J_{0}$. The $R_{s}$ values of these two samples are the lowest among all the samples. The highest value of $R_{\mathrm{sh}}$ was obtained for sample $\mathrm{A}_{2}$. The $R_{s}$ values for all the samples are found to be in between 2 and $3 \Omega \mathrm{cm}^{2}$. The lowest value of $R_{s}\left(2.058 \Omega \mathrm{cm}^{2}\right)$ was obtained for the sample $\mathrm{B}_{3}$. The $n$ values of all the samples are found to be $\sim 2$ but, for the samples $\mathrm{B}_{3}$ and $\mathrm{B}_{4}$, the $n$ value is very high $(\sim 5)$ due to high surface recombination. The $J_{0}$ values for all the samples are found between $2.0 \times 10^{-7}$ and $5.0 \times 10^{-4} \mathrm{~A} / \mathrm{cm}^{2}$. The lowest values of $n$ and $J_{0}$ have been obtained for sample $\mathrm{A}_{2}(1.788$, $\left.2.363 \times 10^{-7} \mathrm{~A} / \mathrm{cm}^{2}\right)$, whereas highest values are obtained for sample $B_{3}\left(5.356,5.211 \times 10^{-4} \mathrm{~A} / \mathrm{cm}^{2}\right)$, respectively.

\section{Conclusions}

Dependence of SiNWs solar cells performance on the concentration of $\mathrm{Ag}$ deposition solution has been investigated. The filling ratio of SiNWs array changed with $\mathrm{AgNO}_{3}$ and 
HF concentration. The diameter of SiNWs is decreased, whereas wire density is increased linearly with increase in $\mathrm{AgNO}_{3}$ concentration. Both the diameter and wire density are decreased with increase in HF concentration. The filling ratio of the SiNWs array is increased with increase in $\mathrm{AgNO}_{3}$ concentration, whereas it is decreased with increase in HF concentration. The minimum reflectance value of $\sim 1 \%$ is achieved for the filling ratio of $\sim 40 \%$. It has been observed that the performance and diode parameters strongly depend on the solution concentration used for $\mathrm{Ag}$ nanoparticle deposition. A maximum short circuit current density of 35.6 $\mathrm{mA} / \mathrm{cm}^{2}$ is obtained for the sample $\mathrm{B}_{4}$. The highest conversion efficiency of $9.73 \%$ is achieved with CF of 0.531 for aqueous solution of $\mathrm{HF}(4.6 \mathrm{M})$ and $\mathrm{AgNO}_{3}(0.03 \mathrm{M})$. The efficiency can be improved with improving the $\mathrm{CF}$ values using better process techniques.

\section{Conflict of Interests}

The authors declare that they have no conflict of interests regarding the publication of this paper.

\section{Acknowledgments}

This work was financially supported by the Pioneer Research Center Program through the National Research Foundation of Korea (2011-0001649) by the Ministry of Science, Ict \& future Planning (MSIP) and partially funded by the Energy International Collaboration Research \& Development Program of the Ministry of Knowledge Economy (MKE) (2011, 8520010050).

\section{References}

[1] N. S. Lewis, “Toward cost-effective solar energy use," Science, vol. 315, no. 5813, pp. 798-801, 2007.

[2] L. Tsakalakos, "Nanostructures for photovoltaics," Materials Science and Engineering R, vol. 62, no. 6, pp. 175-189, 2008.

[3] Y. Huang, X. Duan, and C. M. Lieber, "Nanowires for integrated multicolor nanophotonics," Small, vol. 1, no. 1, pp. 142-147, 2005.

[4] H. Sai, Y. Kanamori, K. Arafune, Y. Ohshita, and M. Yamaguchi, "Light trapping effect of submicron surface textures in crystalline Si solar cells," Progress in Photovoltaics, vol. 15, no. 5, pp. 415-423, 2007.

[5] S. L. Diedenhofen, G. Vecchi, R. E. Algra et al., "Broadband and omnidirectional antireflection coatings based on semiconductor nanorods," Advanced Materials, vol. 21, no. 9, pp. 973-978, 2009.

[6] Y. Chen, Z. Xu, M. R. Gartia, D. Whitlock, Y. Lian, and G. L. Liu, "Ultrahigh throughput silicon nanomanufacturing by simultaneous reactive ion synthesis and etching," ACS Nano, vol. 5, no. 10, pp. 8002-8012, 2011.

[7] R. A. Street, W. S. Wong, and C. Paulson, "Analytic model for diffuse reflectivity of silicon nanowire mats," Nano Letters, vol. 9, no. 10, pp. 3494-3497, 2009.

[8] L. Cao, P. Fan, A. P. Vasudev et al., "Semiconductor nanowire optical antenna solar absorbers," Nano Letters, vol. 10, no. 2, pp. 439-445, 2010.
[9] B. K. Teo and X. H. Sun, "Silicon-based low-dimensional nanomaterials and nanodevices," Chemical Reviews, vol. 107, no. 5, pp. 1454-1532, 2007.

[10] K. Q. Peng, Y. J. Yan, S. P. Gao, and J. Zhu, "Synthesis of largearea silicon nanowire arrays via self-assembled nano-electrochemistry," Advanced Materials, vol. 14, pp. 1164-1167, 2002.

[11] K. Peng, H. Fang, J. Hu et al., "Metal-particle-induced, highly localized site-specific etching of $\mathrm{Si}$ and formation of singlecrystalline Si nanowires in aqueous fluoride solution," Chemistry, vol. 12, no. 30, pp. 7942-7947, 2006.

[12] Z. Fan, R. Kapadia, P. W. Leu et al., "Ordered arrays of dualdiameter nanopillars for maximized optical absorption," Nano Letters, vol. 10, no. 10, pp. 3823-3827, 2010.

[13] J.-Y. Jung, Z. Guo, S.-W. Jee, H.-D. Um, K.-T. Park, and J.-H. Lee, "A strong antireflective solar cell prepared by tapering silicon nanowires," Optics Express, vol. 18, no. 19, pp. A286-A292, 2010.

[14] H. Lu and C. Gang, "Analysis of optical absorption in silicon nanowire arrays for photovoltaic applications," Nano Letters, vol. 7, no. 11, pp. 3249-3252, 2007.

[15] J. S. Li, H. Y. Yu, S. M. Wong et al., "Design guidelines of periodic Si nanowire arrays for solar cell application," Applied Physics Letters, vol. 95, Article ID 243113, 2009.

[16] C. H. Sun, P. Jiang, and B. Jiang, "Broadband moth-eye antireflection coatings on silicon," Applied Physics Letters, vol. 92, Article ID 061112, 2008.

[17] H.-P. Wang, K.-Y. Lai, Y.-R. Lin, C.-A. Lin, and J.-H. He, "Periodic Si nanopillar arrays fabricated by colloidal lithography and catalytic etching for broadband and omnidirectional elimination of fresnel reflection," Langmuir, vol. 26, no. 15, pp. 12855-12858, 2010.

[18] J. W. Leem, Y. M. Song, and J. S. Yu, "Broadband wideangle antireflection enhancement in $\mathrm{AZO} / \mathrm{Si}$ shell/core subwavelength grating structures with hydrophobic surface for Sibased solar cells," Optics Express, vol. 19, no. 19, pp. A1155-A1164, 2011.

[19] H. Bao and X. Ruan, "Optical absorption enhancement in disordered vertical silicon nanowire arrays for photovoltaic applications," Optics Letters, vol. 35, no. 20, pp. 3378-3380, 2010.

[20] C. Lin and M. L. Povinelli, "Optimal design of aperiodic, vertical silicon nanowire structures for photovoltaics," Optics Express, vol. 19, no. 19, pp. A1148-A1154, 2011.

[21] Q. G. Du, C. H. Kam, H. V. Demir, H. Y. Yu, and X. W. Sun, "Broadband absorption enhancement in randomly positioned silicon nanowire arrays for solar cell applications," Optics Letters, vol. 36, no. 10, pp. 1884-1886, 2011.

[22] V. Sivakov, G. Andrä, A. Gawlik et al., "Silicon nanowirebased solar cells on glass: synthesis, optical properties, and cell parameters," Nano Letters, vol. 9, no. 4, pp. 1549-1554, 2009.

[23] T.-H. Pei, S. Thiyagu, and Z. Pei, "Ultra high-density silicon nanowires for extremely low reflection in visible regime," Applied Physics Letters, vol. 99, no. 15, Article ID 153108, 2011.

[24] K. Peng, Y. Xu, Y. Wu, Y. Yan, S.-T. Lee, and J. Zhu, “Aligned single-crystalline $\mathrm{Si}$ nanowire arrays for photovoltaic applications," Small, vol. 1, no. 11, pp. 1062-1067, 2005.

[25] F. Toor, H. M. Branz, M. R. Page, K. M. Jones, and H.-C. Yuan, "Multi-scale surface texture to improve blue response of nanoporous black silicon solar cells," Applied Physics Letters, vol. 99, no. 10, Article ID 103501, 2011.

[26] H. F. Li, R. Jia, C. Chen et al., "Influence of nanowires length on performance of crystalline silicon solar cell," Applied Physics Letters, vol. 98, Article ID 151116, 2011. 
[27] J. Y. Jung, H. D. Um, S. W. Jee, K. T. Park, J. H. Bang, and J. H. Lee, "Optimal design for antireflective Si nanowire solar cells," Solar Energy Materials and Solar Cells, vol. 112, pp. 84-90, 2013. 


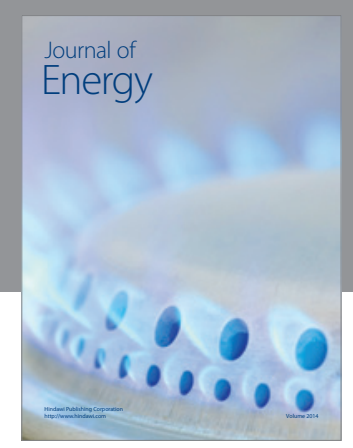

Journal of

Industrial Engineering
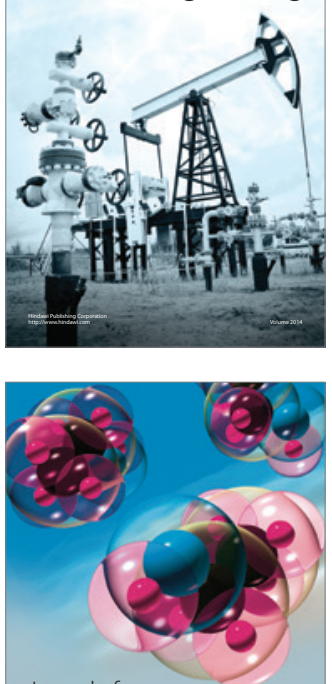

Fuels
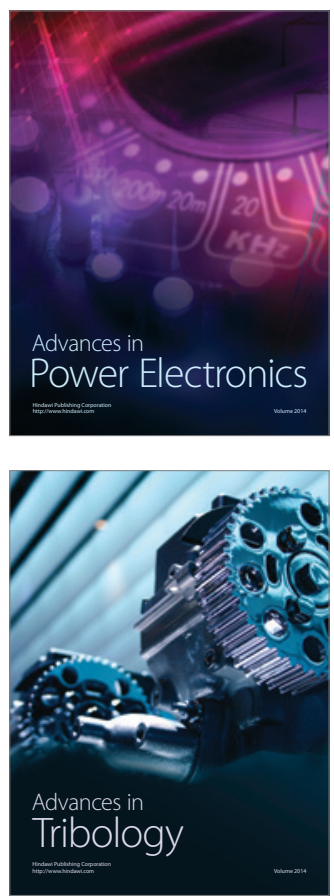

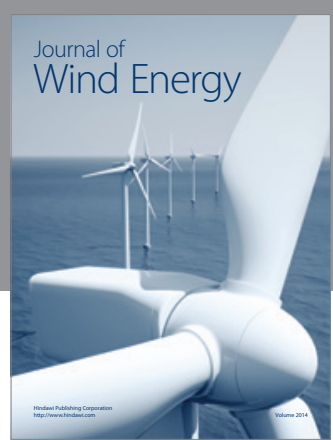

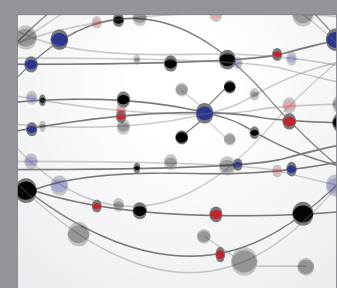

The Scientific World Journal

Submit your manuscripts at http://www.hindawi.com

Journal of

Structures
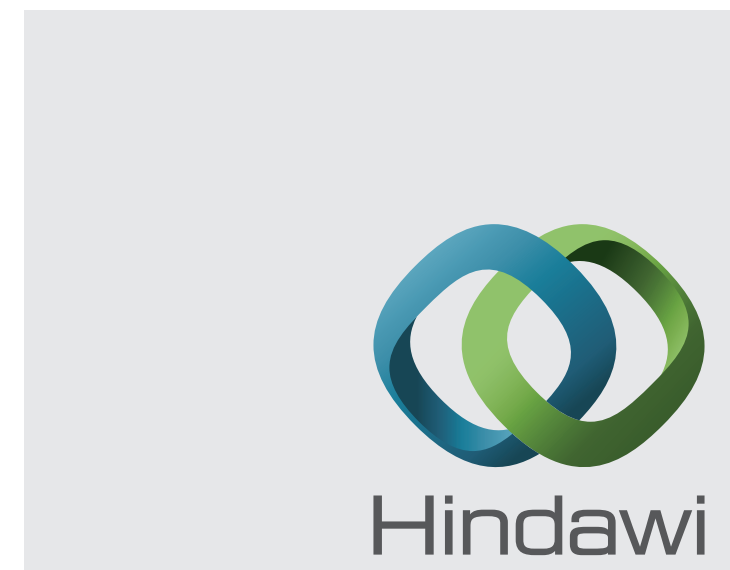

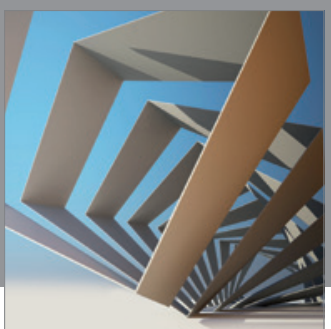

Rotating

Machinery
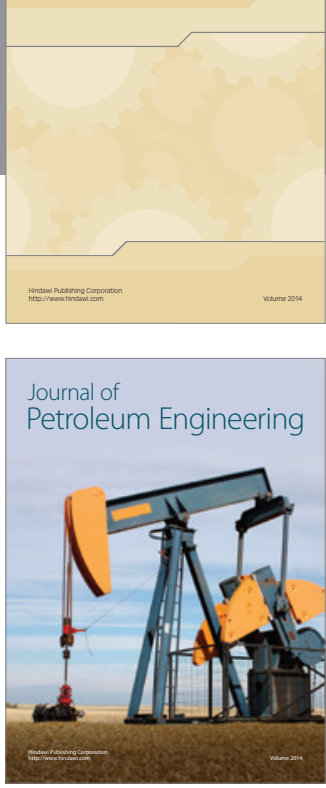

Journal of

Solar Energy
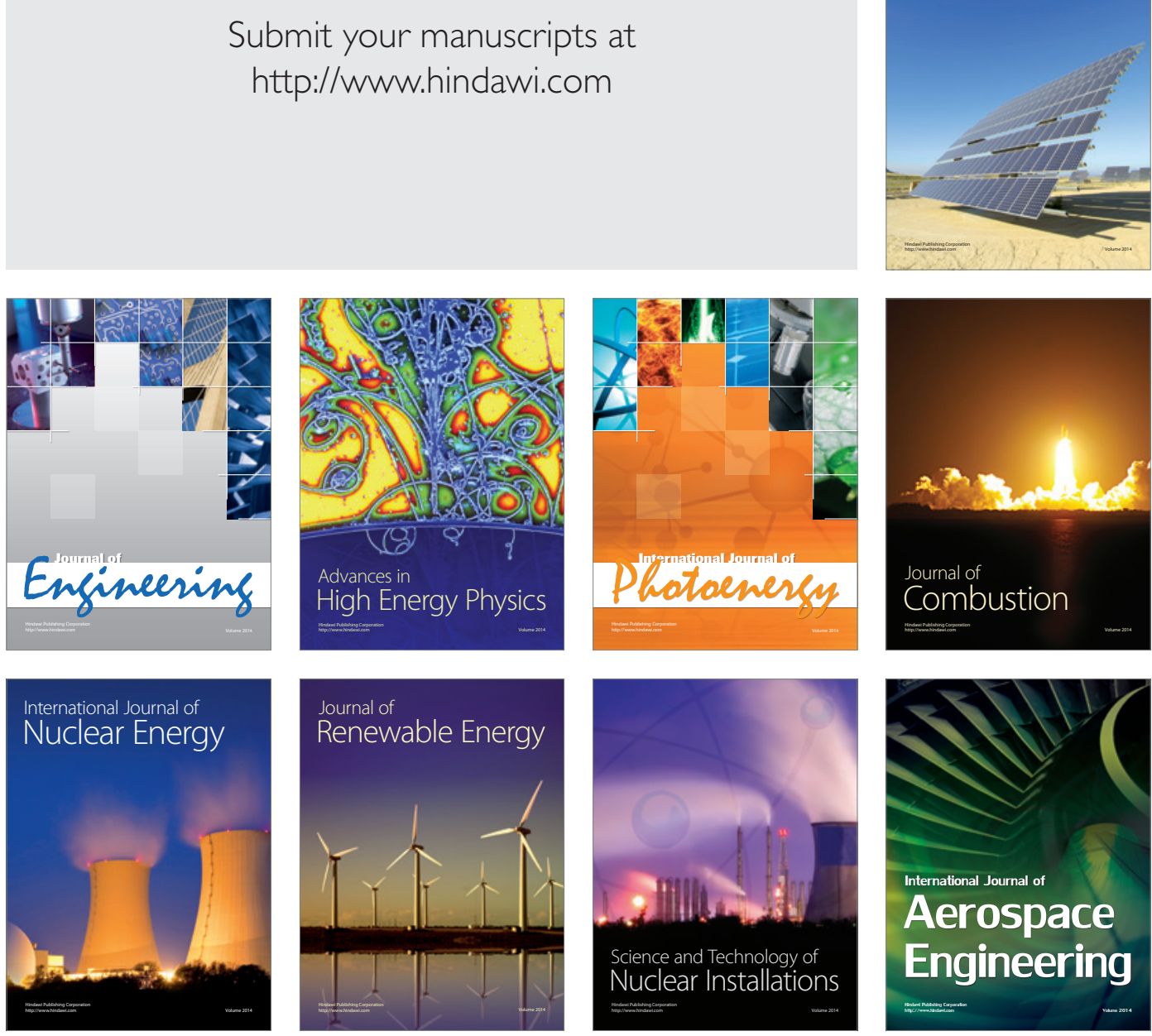